Espacio y Desarrollo N³5, 2020, pp. 99-120 (e-ISSN 2311-5734)

https://doi.org/10.18800/espacioydesarrollo.202001.004

\title{
Variación del Área agrícola en el distrito La Yarada los Palos, Tacna, Perú
}

\author{
Ana Isabel Alvarado Huapaya \\ https://orcid.org/0000-0002-9533-7612 \\ Pontificia Universidad Católica del Perú \\ anai.alvarado@pucp.edu.pe
}

Paloma Capristán Sotelo https://orcid.org/0000-0002-2017-0619

Pontificia Universidad Católica del Perú p.capristan@pucp.edu.pe

Claudia Corahua Benites https://orcid.org/0000-0003-1286-7878

Pontificia Universidad Católica del Perú claudia.corahua@pucp.edu.pe

Carla Ruiz Philipps https://orcid.org/0000-0003-4471-2416 Pontificia Universidad Católica del Perú carla.ruizp@pucp.edu.pe

Gabriela Velásquez Bejarano https://orcid.org/0000-0002-7166-6905 Pontificia Universidad Católica del Perú gabriela.velasquez@pucp.pe

Fecha de recepción: 9/11/2020 Fecha de aceptación: 18/12/2020 


\section{Resumen}

El crecimiento poblacional y el mayor uso de agua subterránea han favorecido la extensión del área agrícola en los últimos veintiún años en el distrito de La Yarada Los Palos. En el presente estudio, se busca analizar los cambios de la extensión agrícola e identificar tendencias a través la teledetección y análisis espacial multitemporal. Se utilizaron imágenes satelitales Landsat 5 TM y Landsat 8 OLI para el periodo 2000-2020 con el fin de identificar usos agrícolas en el área de estudio. Los resultados muestran que la superficie agrícola aumentó en un $265.84 \%$, cifra que se duplicaría en los próximos diez años, según la regresión polinómica. Estos hallazgos brindan una base para la toma de decisiones y gestión de futuros proyectos hídricos, agrícolas y sociales. Palabras clave: expansión agrícola, análisis multitemporal, combinación de bandas, demanda hídrica.

\section{Agricultural areas variation whithin the Yarada de los Palos District, Tacna, Perú}

\section{Abstract}

Population growth and the increasing use of groundwater has favored the extension of the agricultural area in the last twenty-one years in the district of La Yarada Los Palos. In this study, we seek to analyze the changes in agricultural extension and identify trends through remote sensing and multitemporal spatial analysis. Landsat 5TM and Landsat 8 OLI satellite images were used for the period 2000-2020 to identify agricultural uses in the study area. The results show that the agricultural area increased by $265.84 \%$, a figure that would double in the next ten years, according to the polynomial regression. These findings provide a basis for decisionmaking and management of future water, agricultural and social projects.

Keywords: agricultural expansion, multitemporal analysis, band composition, water demand.

\section{INTRODUCCIÓN}

En el Perú, la superficie agrícola indica una expansión de 1648028 hectáreas entre los años 1994 y 2012, lo que representa un crecimiento del 30\% (INEI y MINAGRI, 2012; MINAGRI, 2019). Del total de la superficie agrícola en 2012, solo 4155678 hectáreas (58\%) eran áreas de cultivos (INEI y MINAGRI, 2012). Uno de los departamentos que menos áreas de cultivos presentó, después de Lima y Moquegua, fue Tacna con un total de 36641 hectáreas (INEI, 2014a). A pesar de esto, Tacna se destaca a nivel nacional por su nivel productivo de aceitunas presentes en diversas zonas de la región como en La Yarada Los Palos, considerado uno de los principales distritos productores (BCRP, 2013; Dirección Regional de Agricultura y Región Tacna, 2017; INEI, 2014b).

A lo largo de los últimos veintiún años, La Yarada Los Palos presenta un aumento significativo de su área agrícola. Por lo tanto, para identificar esta variación, se realizó un análisis multitemporal con imágenes satelitales Landsat 5 TM y Landsat 8 OLI. 
Esta metodología ha sido utilizada en estudios previos, como en el avance de la frontera agrícola en el área adyacente al Sistema Sierras de la Ventana en Buenos Aires, Argentina (Marini, 2008); en la expansión de los cultivos de soja en la zona noroeste de Argentina (Paruelo, Guerschman \& Verón, 2005); y en diversos estudios del cambio de uso de suelo en Perú y Latinoamérica (Pineda, 2011; Ruiz, Savé \& Herrera, 2013; Tarrillo, 2019; Zorogastúa, 2011).

En el marco de escasez hídrica y la aproximación hacia el estrés hídrico de la costa peruana, surgen cuestionamientos en torno al uso del agua para el desarrollo agrícola en regiones áridas como Tacna. En ese sentido, en el presente artículo se considera importante analizar el uso de los recursos hídricos dirigidos a la actividad agrícola, y consecuentemente evaluar su sostenibilidad en base a la disponibilidad de agua.

En el área de estudio se han realizado previamente trabajos académicos. Estos han sido relacionados principalmente al agua subterránea disponible en el distrito La Yarada Los Palos: la gestión de los pozos y el agua subterránea, y su adaptabilidad a los cambios ecológicos, sociales y políticos (Rivera, 2018); la sobreexplotación del acuífero del distrito, y sus consecuencias en el nivel freático y la potabilidad del agua (Pino, 2019); la caracterización hidrogeológica del acuífero La Yarada Media (Pino \& Coarita, 2018); y estudios hidrogeológicos de la Cuenca del Río Caplina (Peña et al.; 2009). También se ha elaborado una propuesta para desarrollar infraestructuras administrativas de gestión para mejorar la participación y organización de los vecinos del distrito (Foraquita, 2017).

Pese a los estudios de diferentes temáticas en torno a la localidad, no se han encontrado investigaciones que estudien a profundidad los cambios de la superficie agrícola en el distrito mediante herramientas de teledetección. Ello, a pesar de ser una de las principales zonas de producción de aceitunas a nivel nacional y de presentar acuíferos con calidad y disponibilidad afectados por el aumento de la actividad agrícola (Pino \& Coarita, 2018; Pino, 2019). Por estos motivos, se considera importante y oportuno realizar un análisis multitemporal de la variación de la extensión de la superficie agrícola en el distrito La Yarada Los Palos y analizar las implicancias que puede tener este fenómeno a nivel espacial y de sostenibilidad ambiental. Por ello, el presente artículo busca identificar, para el periodo del año 2000 a 2020, los cambios en la superficie agrícola en términos espaciales y estadísticos en el distrito La Yarada Los Palos.

\section{2. ÁREA DE ESTUdio}

El distrito La Yarada Los Palos ubicado en la provincia de Tacna, departamento de Tacna (Figura 1) se crea a través de la Ley $\mathrm{N}^{\circ} 30358$ el 8 de noviembre de 2015 con intereses políticos para afianzar la presencia del Estado en la zona de frontera del país con Chile (Ley N³0358, 2015; Rivera, 2018). Previo a su creación era un espacio considerado 
Figura 1. Mapa de ubicación del distrito
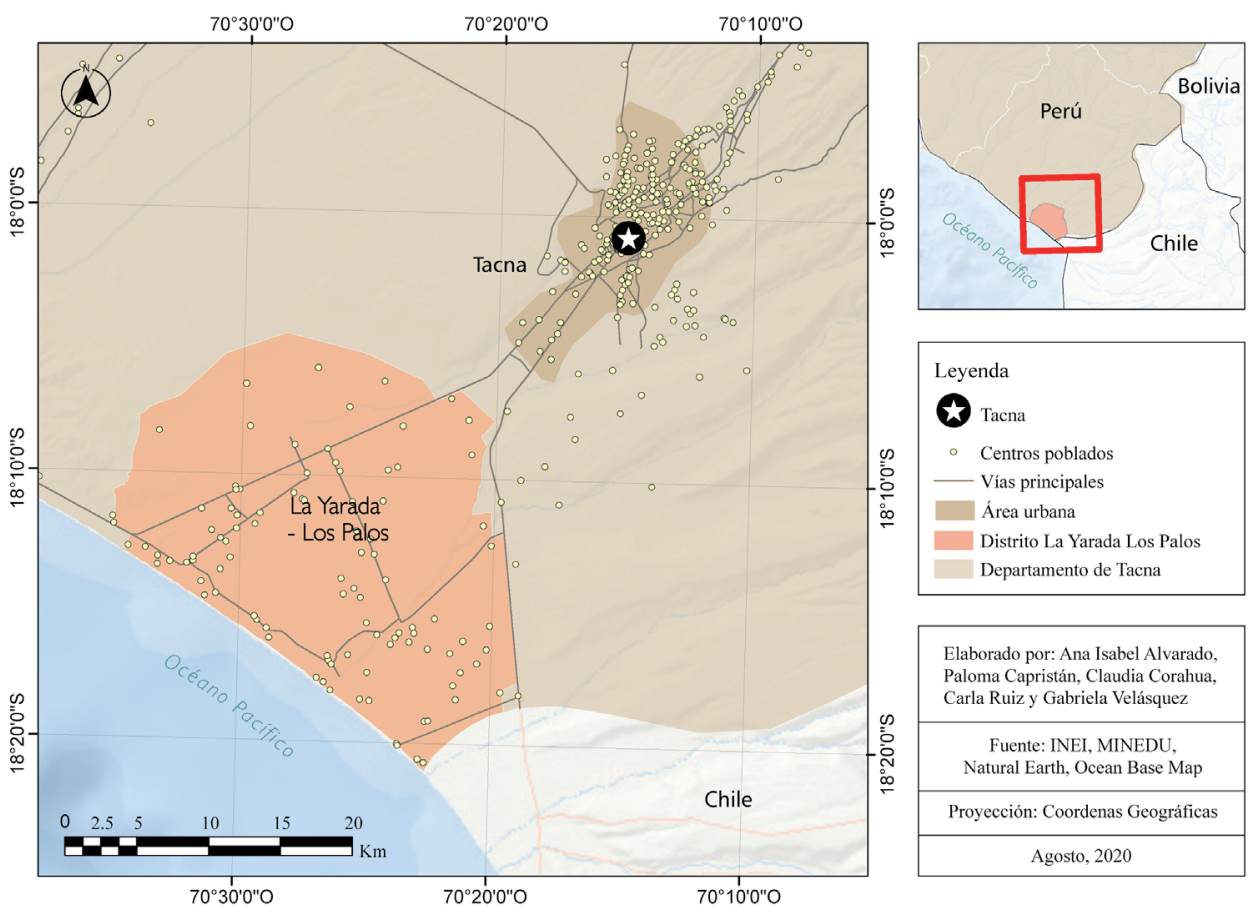

Elaborado por: Ana Isabel Alvarado, Paloma Capristán, Claudia Corahua, Carla Ruiz y Gabriela Velásquez

Fuente: INEI, MINEDU, Natural Earth, Ocean Base Map

Proyección: Coordenas Geográficas Agosto, 2020

como «zona de irrigación»; sin embargo, el convertirse en «distrito» significó una variación en el régimen jurídico, en la administración y en las prioridades del Estado sobre este territorio. Con esto, el gobierno peruano buscó atender las necesidades básicas de la población e incorporarlas en la dinámica del desarrollo nacional (PCM, 2015).

Asimismo, la condición de frontera significó que la demarcación territorial fuera tratada de manera especial y prioritaria por la Dirección Nacional Técnica de Demarcación Territorial (PCM, 2015), según la Ley de Demarcación y Organización Territorial (Ley No 27795). Esto se realiza con la finalidad de contribuir al desarrollo económico y social del distrito, manifestar la soberanía del Estado peruano en el área y no ponerlo en situación de vulnerabilidad.

\subsection{Caracterización física}

El área de estudio se encuentra en la zona de vida del Desierto Desecado Templado Cálido, con poca precipitación y temperaturas templadas (ONERN, 1976). Además, se ubica principalmente sobre una terraza aluvial de escasa pedregosidad y relieve plano conformada por suelos de arena fina y gruesa con drenaje interno excesivo y permeabilidad rápida (Municipalidad Distrital La Yarada Los Palos, 2018). Asimismo, 
al noroeste de La Yarada Los Palos se registra un área con pendientes más pronunciadas. Esta conforma tan solo el 9,22\% del territorio del distrito respecto al área total de 53864 hectáreas.

En cuanto a la estacionalidad, se identifican dos temporadas: la primera abarca los meses de diciembre a marzo, periodo en que el promedio de temperaturas es mayor a $20^{\circ} \mathrm{C}$ y registra una precipitación menor a 0,1 milímetros por mes. La segunda temporada abarca los meses de abril a noviembre, donde las temperaturas promedio son menores a $20^{\circ} \mathrm{C}$, y alcanza un promedio mínimo entre los meses de junio a septiembre, al igual que un aumento de la precipitación de más de 0,1 milímetros por mes.

\subsection{Caracterización social}

Antes de su creación, este territorio se encontraba dentro del distrito de Tacna y tenía una ocupación poblacional de 3998 personas (INEI, 2007 en Municipalidad Distrital de La Yarada Los Palos, 2018). Para el último censo del año 2017 realizado por el INEI, la población fue de 6433 habitantes. Asimismo, se señala que el 86\% de la población censada llevaba cinco ańos o más viviendo en el área (INEI, 2017). El 14\% restante de la población actual proviene principalmente del departamento de Puno, otros distritos del departamento de Tacna y, en menor proporción, de Lima, Cusco y Moquegua (INEI, 2017). Junto con los censos, también existe información poblacional de La Yarada Los Palos generada por la Municipalidad del distrito. A diferencia del INEI, en los estudios municipales la población se calcula en aproximadamente 16432 habitantes (Municipalidad Distrital de La Yarada Los Palos, 2018).

La Yarada Los Palos es categorizado como un distrito rural (INEI, 2017). Este territorio se encuentra en el quintil superior de distritos con menor desarrollo en el país con un índice de desarrollo humano de 0,549 (PNUD, 2018). Los indicadores con los que mejor se evidencia esta situación se relacionan principalmente con el aspecto educativo, ya que solo el $60 \%$ de la población cuenta con educación secundaria completa. Por otra parte, se observan atrasos en cuanto a los servicios básicos. Por ejemplo, el $40 \%$ de las viviendas no cuentan con alumbrado eléctrico y solo el $7 \%$ tienen una red pública de agua dentro de ellas, por lo que la principal fuente de agua son pozos subterráneos (INEI, 2017).

De los habitantes censados por el INEI, el 75\% o 4807 personas se encuentran en edad de trabajar (PET). Hasta el momento en el que se realizó el Censo Nacional, el 60\% del total de la PET del distrito contaba con un empleo (INEI, 2017). Las actividades económicas son, en su mayoría, relacionadas con los trabajos agrícolas, la pesca artesanal, el comercio y ocupaciones elementales (INEI 2017; Municipalidad Distrital de la Yarada Los Palos, 2018). 


\subsection{Actividad agrícola}

En cuanto a la producción agrícola, en el año 2011 la producción de aceituna en el departamento de Tacna fue del $75 \%$ de la producción nacional, con un rendimiento promedio de 6,8 toneladas métricas por hectárea, superior al nacional de 5,6 TM/ha. Este aumento de producción no solo se debe al incremento del rendimiento del suelo sino también por la expansión del área sembrada (BCRP, 2013). Por ejemplo, para el año 2011 el área sembrada para el cultivo de aceituna fue de 11327 hectáreas, mientras que para el año 2018 esta aumentó a 22974 hectáreas (MINAGRI, s.f).

Respecto al distrito La Yarada Los Palos, al igual que a nivel departamental, el principal cultivo es el olivo, seguido la alfalfa y el maíz (Municipalidad Distrital de La Yarada Los Palos, 2018). En la Figura 2 se puede observar el crecimiento del área sembrada para la aceituna, que en cuatro años aumentó en más de 7000 hectáreas, lo cual sitúa a la aceituna como el cultivo principal del distrito. En cambio, el crecimiento de los demás cultivos abarca menor área sembrada y se observa un menor crecimiento. Incluso, el cultivo de maíz, segundo cultivo más importante, ha disminuido con el pasar de los años al igual que la quinua, mientras que los frutales como la tuna y la naranja tienden al aumento (MINAGRI, s.f).

Figura 2. Área sembrada en el distrito La Yarada Los Palos (2015-2019)
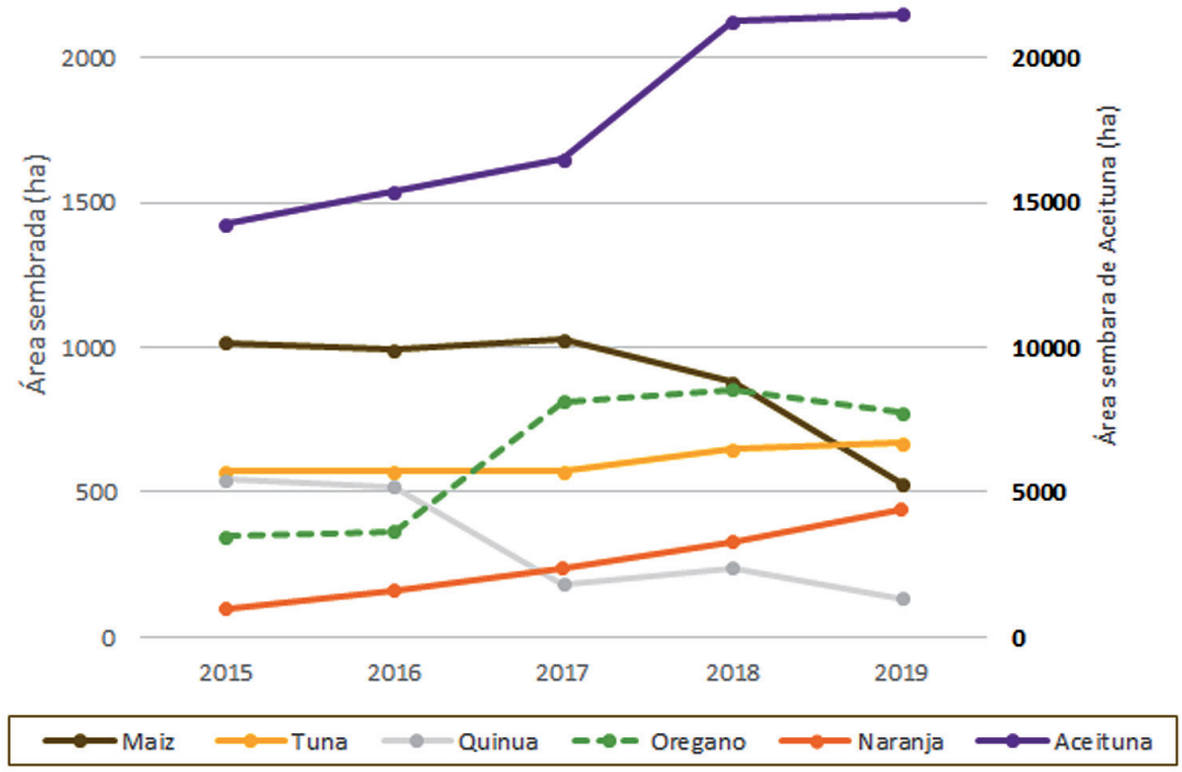

Fuente: Elaboración sobre la base de MINAGRI - Perfil productivo regional. 
El interés por parte del Estado en esta área se evidencia desde mediados del siglo $\mathrm{XX}$, a través de la promoción de proyectos de irrigación lo cual incentivó la expansión agrícola (Rivera, 2018). Actualmente, en esta región existen diversos programas de desarrollo agrícola impulsados por el gobierno regional, los gobiernos locales y los productores-exportadores, agrupados en asociaciones de pequeños productores con tierras propias y producción de terceros (BCRP, 2013). Un ejemplo de esto fue el proyecto de mejoramiento de las capacidades y asistencia técnica para el cultivo y producción del olivo en La Yarada Los Palos, el cual significó una inversión de 1372971 soles entre los años 2019 y 2020 (Municipalidad Distrital de La Yarada Los Palos, 2020.).

\subsubsection{Pozos subterráneos}

Debido a que el distrito en estudio se ubica en una zona desértica, el uso del agua para el desarrollo de la actividad agrícola cumple un papel fundamental. Ante esto, el acuífero costero La Yarada ha sido uno de los principales sustentos para esta actividad y se ha accedido a este a través de pozos. Estos pozos, construidos en su mayoría en la primera mitad del siglo XX, pasaron por un proceso de electrificación que permitió la ampliación de la frontera agrícola en la década de 1960 (Rivera, 2018). En el año 1976 la región de Tacna registró 27566 predios en la zona costera que abarcaban una superficie bajo riego de 28601 hectáreas. De estas, 2423 predios catastrados corresponden a La Yarada Los Palos, siendo este el distrito con mayor superficie de riego con 5058 hectáreas, regadas con agua subterránea a través de un sistema compartido entre gravedad y riego tecnificado. Desde ese periodo, el número de pozos ha tenido un aumento gradual a través de los años (Tabla 1 ).

Tabla 1. Pozos, disponibilidad de agua para agricultura según año

\begin{tabular}{cccc} 
Año & Pozos & mm/año & Hectáreas (ha) irrigadas \\
\hline 1967 & 31 & 13 & - \\
\hline 1971 & 55 & 27 & 2000 \\
\hline 1976 & 70 & 30 & 28000 \\
\hline
\end{tabular}

Fuente: Elaborado sobre la base de los datos de la Municipalidad Distrital de La Yarada Los Palos, 2018.

Desde el año 1984 estaba prohibida cualquier perforación de pozos en el acuífero (Rivera, 2018). Con la intención de formalizar las perforaciones existentes, en el año 2015 entra en vigor el Decreto de Supremo 07-2015-MINAGRI para formalizar y regularizar el funcionamiento de los pozos no autorizados. No obstante, esta regularización 
terminó promoviendo las perforaciones indiscriminadas (Pino, 2019; Rivera, 2018). Como resultado, la cantidad de agricultores con pozos informales incrementó considerablemente: se calcula que existe una proporción de 8000 usuarios informales y 1000 usuarios formales (Rivera, 2018).

Si bien esta intensa explotación del acuífero en conjunto con la agroindustria de la zona ha posicionada a la región como el primer productor de aceitunas a nivel nacional, también ha tenido implicancias en la cuenca. Para el caso del acuífero La Yarada, el balance hídrico entendido como la diferencia entre los aportes y las pérdidas de agua en un espacio y tiempo determinado, se ha visto afectado pasando de ser positivo $(+15,5)$ en el año 1989, a ser negativo $(-44,0)$ diez años después. Además, se ha encontrado que, a partir de los ańos 80 , la sobreexplotación ha provocado el descenso del nivel freático y la potabilidad del agua ha pasado de ser aceptable a deficiente (MINEM, 2020; Pino, 2019). Esta disponibilidad de agua, junto a las técnicas de explotación del acuífero mediante pozos, abre un espacio para reflexionar sobre la sostenibilidad de las prácticas agrícolas, así como sobre el uso y manejo de los recursos hídricos.

\section{Metodología}

\subsection{Colección de data}

Para el desarrollo de este estudio, fue necesario utilizar imágenes de dos satélites Landsat (Tabla 2) para cubrir el periodo seleccionado de veintiún años (2000-2020). En primer lugar, se utilizó el Landsat 5 TM, que capturó imágenes desde 1984 hasta el año 2013; este sistema posee ocho bandas espectrales. En segundo lugar, el Landsat 8 OLI, aún en órbita, posee once bandas y fue utilizado para el periodo restante de 2013 a 2020 (Ariza, 2013).

En cuanto al aspecto hídrico en la investigación, la recolección de datos sobre la ubicación de los pozos en el área de estudio, se utilizó la información espacial que pone a disposición la Autoridad Nacional del Agua (ANA, 2017).

\subsection{Análisis multitemporal}

En el presente estudio se optó por una secuencia de imágenes con periodos de cada cinco años, con el fin de obtener en hectáreas un registro de la extensión agrícola durante los intervalos de tiempo seleccionados. Se escogió la temporada de diciembre a marzo, en la cual las temperaturas en promedio son mayores, la precipitación es menor y hay menor nubosidad. Por tanto, las imágenes poseen una cobertura de nubes menor al $10 \%$, lo que facilitó la identificación de los cultivos en los años seleccionados. Así se obtuvieron tres imágenes satelitales de Landsat 5 TM para los años 2000, 2005 y 2010; y dos imágenes del Landsat 8 OLI para los años 2015 y 2020. 
Tabla 2. Metadata de las imágenes satelitales

\begin{tabular}{|c|c|c|c|c|c|c|}
\hline Código de escena & Fecha & Satélite & $\begin{array}{l}\text { Resolución } \\
\text { espacial }\end{array}$ & $\begin{array}{l}\text { Resolución } \\
\text { radiométrica }\end{array}$ & $\begin{array}{c}\mathrm{N}^{\circ} \\
\text { Bandas }\end{array}$ & Fuente \\
\hline LT50020732000081CUB00 & $21 / 03 / 2000$ & & & & & \\
\hline LT50020732005078COA01 & $19 / 03 / 2005$ & \multirow[t]{2}{*}{$\begin{array}{c}\text { Landsat } \\
5 \mathrm{TM}\end{array}$} & & 8 bits & $\begin{array}{l}\text { Ocho } \\
(8)\end{array}$ & \\
\hline LT50020732010364CUB00 & $30 / 12 / 2010$ & & $30 \mathrm{~m}$ & & & USGS \\
\hline LC80020732015090LGN02 & $31 / 03 / 2015$ & \multirow{2}{*}{$\begin{array}{c}\text { Landsat } \\
8 \text { OLI }\end{array}$} & & \multirow[t]{2}{*}{16 bits } & \multirow{2}{*}{$\begin{array}{c}\text { Once } \\
(11)\end{array}$} & \\
\hline LC80020732020056LGN00 & $25 / 02 / 2020$ & & & & & \\
\hline
\end{tabular}

Fuente: Elaborado sobre la base de USGS, s.f.

\subsection{Combinación de bandas para usos agrícola}

Tras escoger las imágenes satelitales, fue necesario exportarlas al SIG ArcMap 10.5 para la realización de la combinación de bandas: $(S W I R-N I R) \div(S W I R+N I R)$. Este consiste en discriminar las parcelas agrícolas en base al principio físico de reflectancia y absorción (Ramos, 2019). Al realizar el contraste de imágenes son necesarias las bandas espectrales de onda corta infrarroja (SWIR) e infrarrojo cercano (NIR). En el caso del Landsat 5, la banda SWIR abarca el rango de 1,55 a 1,75 $\mu \mathrm{m}$ (banda 5), es decir es el rango del espectro electromagnético donde las parcelas producen mayor reflexión. Mientras que la banda de NIR representa la banda de absorción con un rango de 0,76 a $0,90 \mu \mathrm{m}$ (banda 4) del espectro electromagnético. Por otra parte, en el satélite Landsat 8 la banda SWIR abarca 1,57 a 1,65 $\mu \mathrm{m}$ (banda 6) y la banda NIR, 0,85 a $0,88 \mu \mathrm{m}$ (banda 5) (USGS, s.f.). El contraste entre las bandas espectrales mencionadas es obtenido a través del Álgebra de mapas para crear y ejecutar una expresión matemática en un nuevo ráster. El resultado de las operaciones entre ambas bandas es representado en el nuevo ráster de salida, para obtener una imagen donde se destacan las parcelas agrícolas.

\subsection{Proyecciones}

Para estimar el futuro desarrollo de las áreas cultivadas se realizaron estimaciones de la serie de datos en modelos de regresión lineal, exponencial y polinómica; para esto se utilizaron las hectáreas ocupadas por agricultura obtenidas del análisis multitemporal. Además, se utilizó el estadístico del $\mathrm{R}^{2}$ para medir la bondad del ajuste del modelo y hallar el nivel de relación entre los años y el espacio agrícola (Klitgaard, 2011). Asimismo, se realizó una extrapolación para conocer los posibles valores a futuro que tendría la serie y se complementaron con las áreas del distrito en donde se daría esta expansión. 


\section{Resultados}

Como resultados del análisis multitemporal de la superficie agrícola en el distrito de La Yarada Los Palos se obtuvo cuatro productos: un mapa multitemporal de la extensión agrícola, una tabla comparativa, un mapa de la distribución de pozos, y un gráfico de tendencias. Estos productos cartográficos y estadísticos permiten discutir más a fondo el problema de investigación.

\subsection{Mapa multitemporal de la extensión agrícola}

El mapa presentado en la Figura 3 muestra espacialmente la expansión de la superficie agrícola en el lugar de estudio para el periodo del año 2000 a 2020. En este rango se puede notar que el incremento de la actividad agrícola se ha ubicado principalmente en la parte central del distrito con una tendencia orientada hacia la zona costera. Además de esta zona, el área ubicada al norte del distrito también presenta un sector donde se aprecia la concentración de cultivos. La expansión se da de forma dispersa, es decir, el área de cultivo no se presenta necesariamente de forma aglomerada. Este patrón se

Figura 3. Mapa multitemporal de la extensión de la superficie agrícola en el distrito La Yarada Los Palos, Tacna
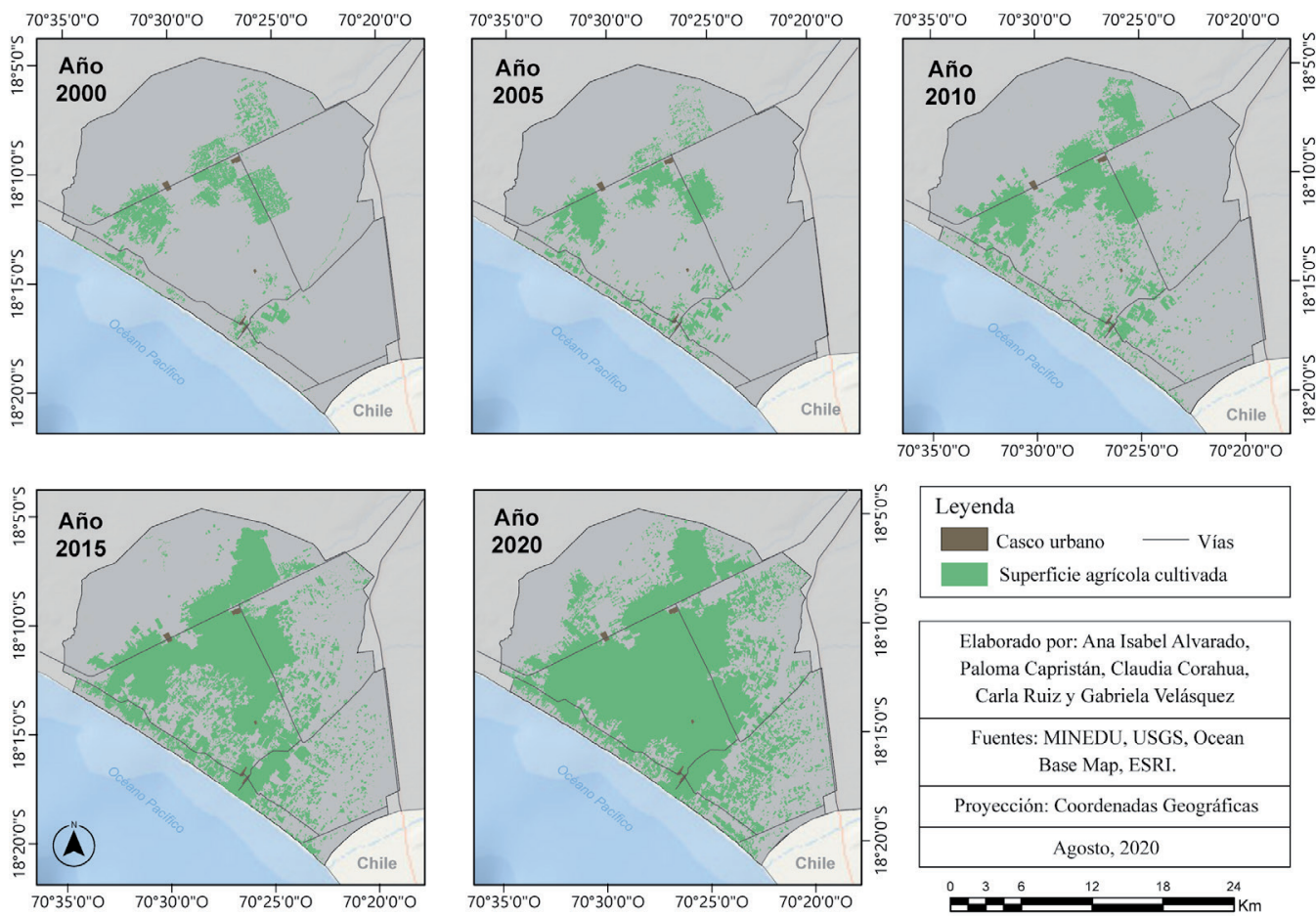
evidencia principalmente en los primeros kilómetros más cercanos a la línea costera, en la parte sur y sureste del distrito. La variación de la extensión de la superficie agrícola (Tabla 3) muestra el aumento de 15219 hectáreas en el periodo de veintiún ańos.

Tabla 3. Variación la superficie agrícola (en hectáreas) de a acuerdo a la densidad de cultivos

\begin{tabular}{lccccc}
\multicolumn{1}{c}{ Ańo } & $\mathbf{2 0 0 0}$ & $\mathbf{2 0 0 5}$ & $\mathbf{2 0 1 0}$ & $\mathbf{2 0 1 5}$ & $\mathbf{2 0 2 0}$ \\
\hline Área (ha) & 5724,81 & 7191,18 & 7555,14 & 16125,93 & $\mathbf{2 0 ~ 9 4 3 , 8 6}$ \\
\hline \% respecto al área total & $10,62 \%$ & $13,35 \%$ & $14,02 \%$ & $29,94 \%$ & $\mathbf{3 8 , 8 8 \%}$ \\
\hline
\end{tabular}

\subsection{Mapa de distribución de pozos agrícolas}

En la Figura 4 se muestra un mapa en el que se compara la situación de la extensión agrícola en 2010 y en 2020. A esta información se le agrega la ubicación de los pozos en el distrito La Yarada Los Palos que datan del año 2009 para ambos casos. En el mapa se observa que el crecimiento del área agrícola coincide con el patrón de distribución de los pozos.

Figura 4. Mapa de distribución de pozos agrícolas en el distrito La Yarada Los Palos, Tacna

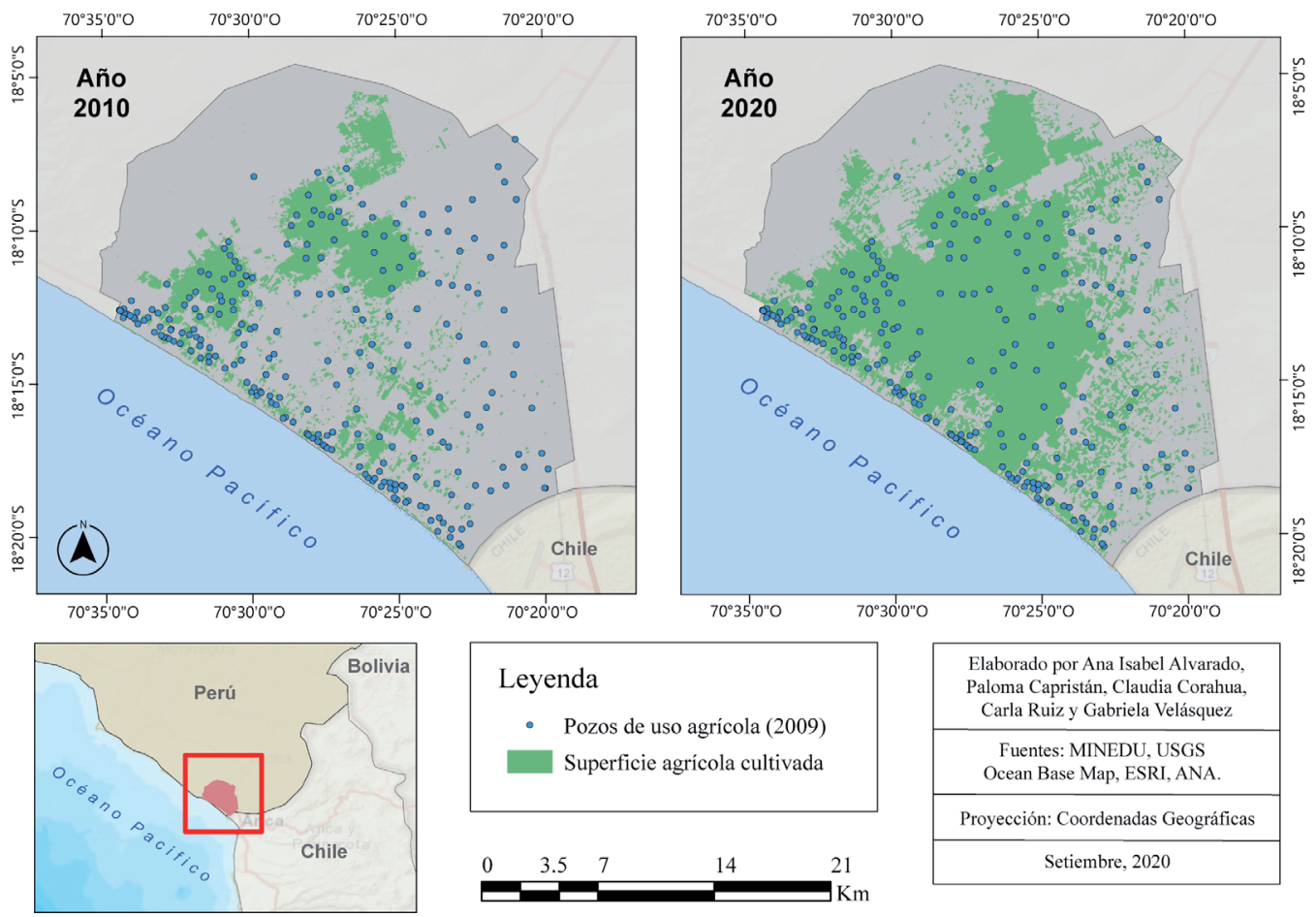


Figura 5. Área total cultivada por año en el distrito La Yarada Los Palos, Tacna

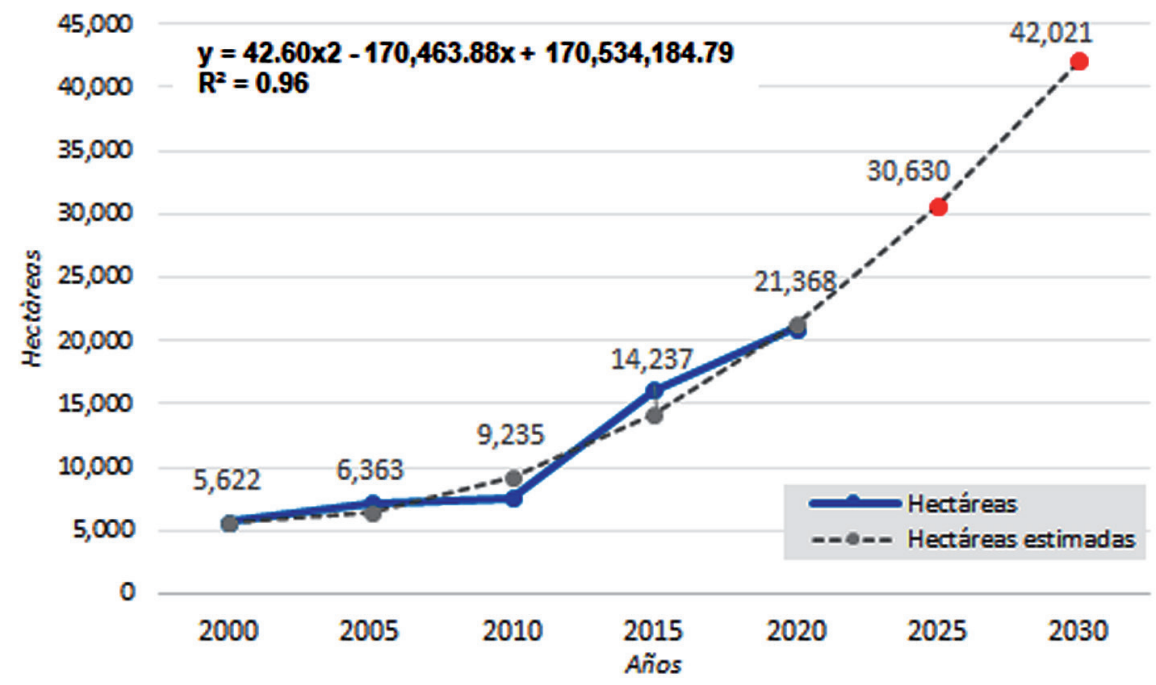

\subsection{Proyecciones para el área de cultivo}

En la Figura 3 se presenta el área total cultivada por año en el distrito La Yarada Los Palos. Los datos presentes entre los años 2000 y 2020 facilitaron la aplicación de la tendencia, la cual es expresada por la curva presente en el gráfico de la Figura 5. La idoneidad del modelo elegido se determinó en base $\mathrm{al}^{2}$ y a la realización de un diagrama de residuos (Frías, Fernández \& Sordo, 2012). En este sentido, se determinó que la serie de datos seguía una tendencia polinómica. Estos datos sirvieron de base para determinar las proyecciones para los años 2025 y 2030.

De tal forma, para 2025 se estima que, de seguir con la tendencia de crecimiento actual, el distrito La Yarada Los Palos aumentaría en 9686 hectáreas la superficie agrícola cultivada. De acuerdo con la ecuación polinómica, la proyección para 2030 es de 42021 hectáreas. Es decir, en un periodo de diez años se duplicarían las hectáreas cultivadas. Sin embargo, al considerar el porcentaje correspondiente al área de pendientes más pronunciadas $(9.22 \%)$, el área ocupada por concentraciones de viviendas $(0,2 \%)$, el área cubierta por las vías de transporte $(0,06 \%)$ y el área agrícola actual $(38,8 \%)$, por lo que el $48,28 \%$ del distrito ya estaría ocupado. Esto significa que solo $51,72 \%$ (27 858,46 hectáreas) del espacio tiene el potencial para ser de uso agrícola. En este sentido, de 2020 a 2030 el área agrícola sí podrá incrementar en el 200,64\% (21 067 hectáreas), y contar en 2030 con 6791,46 hectáreas disponibles para otros usos, en el caso que los acuíferos en el distrito no se agoten o que el riego tecnificado se mantenga en los niveles actuales. 


\section{Discusión}

\subsection{Factores influyentes en la variación del espacio agrícola}

El área ocupada por cultivos agrícolas en el distrito La Yarada Los Palos en el periodo 2000-2020 se extendió unas 15 219,05 ha, lo que equivale a un crecimiento del $265,84 \%$. Esta expansión podría explicarse a partir de las características sociales del distrito ya que se distingue una relación entre el crecimiento poblacional y la extensión de las áreas de cultivo. Según los datos del censo, entre los ańos 2007 y 2017, la población del distrito se duplicó, periodo que coincide con el aumento del espacio cultivado. Además, cabe resaltar que un porcentaje significativo se dedica a actividades económicas con la agricultura y la pesca en el distrito (INEI, 2017).

Respecto al aumento de la producción de aceitunas, cabe resaltar que los datos utilizados para la comparación de producción y exportación son de la región Tacna. Aun así, esta comparación es viable debido a que el área de estudio representa más del $90 \%$ de la superficie cultivada de olivos en este departamento (Agencia Agraria, s.f., citado por Dirección Regional Agricultura, 2017).

En este sentido, los registros muestran un aumento importante tanto de la producción como de la exportación de este producto, especialmente entre los años 2010, en el que se registra un total de 44670 toneladas en producción y 16673 toneladas para exportación; y 2014, año en el que la producción alcanzó las 115351 toneladas de producción y 24803 toneladas para exportación, casi triplicando su producción en un periodo de cuatro ańos (SUNAT, s.f, \& OEE-MINAG, s.f, citado por Dirección Regional Agricultura, 2017). Este hecho se considera importante ya que se encuentra dentro del periodo de tiempo en el que se registra un mayor crecimiento de área cultivada en el distrito (ver Figuras 3 y 6), por lo que se puede corroborar la existencia de una relación directa entre el aumento de la producción y exportación y el área cultivada. De igual manera, al tomar en cuenta la Figura 2 se observa un aumento significativo de área sembrada de olivo ubicada entre los años 2015 y 2018, por lo que se asume que este ha sido el cultivo que ha ido de la mano con el crecimiento de área agrícola; mientras que los demás cultivos han ido decreciendo en ese mismo periodo (MINAGRI, s.f.). No obstante, este no es el único factor que influye en este ámbito, ya que a partir de 2015 las cifras de exportación y, en particular, de producción disminuyeron significativamente, a pesar del constante crecimiento de las zonas de cultivo en el área.

\subsection{Clasificación y ocupación de áreas}

Una vez analizada la extensión de la superficie agrícola y sus posibles causas, se considera relevante comparar esta información espacial con la del Plan General de Usos de Suelo, el cual forma parte del Plan de Desarrollo Urbano Rural La Yarada Los Palos 2018-2028. 
Esta información está presentada en forma de mapa (Anexo 1) en el cual se revela que el suelo del distrito está clasificado en dos grandes grupos: «urbanizable», el cual contiene tres subgrupos, y «no urbanizable», el cual comprende siete subgrupos.

Si bien el distrito La Yarada Los Palos está dividido en diez subgrupos de uso de suelo, la categoría que tiene mayor predominancia es la de «no urbanizable protección agrícola» (NU-PA). Debido a que esta área ocupa la mayor extensión, existe una mayor probabilidad de que las parcelas agrícolas coincidan con la clasificación de NU-PA dada por la municipalidad.

En contraste a esta situación, también se identificaron áreas en donde la superficie agrícola no coincidía con la categoría mencionada previamente, pues se evidenciaron zonas de cultivos en espacios de la categoría «no urbanizable pecuario» (NU-Pec), «no urbanizable histórico cultural» (NU-HC), y «urbanizables».

En primer lugar, el área NU-Pec, está asignada a la actividad económica relacionada a la crianza de ganado, y no a la actividad agrícola, tal y como se presenta en la zona noroeste del distrito. Sin embargo, esta ocupación no es tan significativa. Lo mismo sucede con la zona NU-HC presente en el distrito, con la diferencia de que esta ocupación se presenta en la parte noreste. En cuanto a los espacios «urbanizables» presentes en el sector sur costero, se mantiene la discrepancia entre la clasificación y los usos. Por el contrario, en los espacios «urbanizables» de la parte central del distrito no se evidenció un traslape con las áreas de cultivo.

Según las proyecciones basadas en la tendencia de la superficie agrícola del distrito, las áreas cultivadas seguirán creciendo conforme pase el tiempo. Lo favorable sería asegurar que este crecimiento se dé dentro del espacio asignado para tales fines: NU-PA no ocupado. Este uso de suelo se distribuye principalmente en la parte centro y sur, en donde las áreas cultivadas son bastante dispersas y pequeñas.

A pesar de esta disponibilidad de áreas, el crecimiento estará condicionado por otros factores, como la presencia de pendientes pronunciadas, redes viales, concentración de viviendas y distribución de pozos. Sobre este último, se evidencia que el área de la categoría NU-PA no ocupada por espacios agrícolas, cuentan con poca presencia de pozos, a comparación de la cantidad que se encuentran en la zona costera (Figura 4). Esto da pie a otro debate sobre la sostenibilidad hídrica del lugar, y sobre la cantidad de recursos con los que se cuenta para cubrir la demanda.

\subsection{Agricultura y sostenibilidad ambiental}

En La Yarada Los Palos la agricultura se ha mantenido como una de las actividades económicas principales. Esta dinámica implica el aprovechamiento de los recursos naturales, los cuales se encuentran cada vez más escasos y limitados (Zarta, 2018). Frente a ello, desde la década de 1990 el concepto de sostenibilidad ha ido evolucionando, 
para finalmente englobar a aquellos procesos o sistemas que reconocen el límite de los recursos, y busca alternativas para el manejo integrado y buen aprovechamiento de estos (Zarta, 2018).

Respecto a la sostenibilidad de los recursos hídricos, la explotación del acuífero frecuentemente tiene efectos positivos importantes en las regiones que lo aplican, siendo el aspecto económico el más beneficiado ya que constituye una posibilidad de desarrollo (Pulido, 2001). En el área de estudio, la explotación del acuífero, a través de pozos, beneficia directamente a la agricultura; especialmente al cultivo del olivo, el cual requiere de un aproximado de 6000 a $8000 \mathrm{~m}^{3}$ de agua por hectárea al año (Gobierno Regional de Coquimbo, 2000).

Sin embargo, estos también generan impactos negativos, sobre todo en el medio natural. Entre estas consecuencias negativas directas está la pérdida de la capacidad total de almacenamiento del acuífero. Además, al considerar que este es un acuífero costero, la explotación y disminución de nivel piezométrico — nivel al que asciende el agua a través de un pozo por capilaridad — puede también provocar una mayor penetración del agua marina y zona de mezcla (Custodio, 1996). El descenso del nivel piezométrico también puede aumentar los costos de explotación ya que la altura de elevación del bombeo aumenta y con esto, el consumo energético. Asimismo, la explotación del acuífero podría movilizar, extraer aguas de baja calidad y afectar el régimen hídrico de los ríos conectados al acuífero (Pulido, 2001).

Entre las consecuencias negativas indirectas, el riego con aguas subterráneas puede provocar la salinización del suelo y a su vez, causar su desertización. Así también, la explotación puede inducir subsidencia del terreno, ya que los acuíferos al estar vacíos provocan inestabilidad en el subsuelo. Por último, pueden causar cambios en sus propiedades físicas ya que se alteran los potenciales hidráulicos al cambiar la dirección de flujo provocado por los bombeos intensivos (Pulido, 2001).

Ante estas implicancias negativas de la explotación, en 1984 el gobierno peruano prohíbe la perforación de pozos en el acuífero de La Yarada. Asimismo, en 1989 se publica la Resolución Ministerial 00555-89-AG/DGAS que prohíbe cualquier nueva excavación o alumbramiento de aguas subterráneas en La Yarada y Hospicio (Rivera, 2018).

Sin embargo, estos mecanismos legales a favor de la conservación del acuífero se encuentran en contradicción con las políticas del Estado y programas para el desarrollo agrícola. Por ejemplo, en 1991 el Decreto Supremo 134-91-PCM otorgó un subsidio a la energía eléctrica para los agricultores, lo que favorece la extracción intensiva del agua de los pozos. De forma similar, en 2015 se publicó el Decreto Supremo 007-2015MINAGRI que permite a los agricultores formalizar sus derechos de uso de agua y obtener licencias para usos con fines agrícolas, lo que aumenta la posibilidad del aumento del número de pozos y pone aún más en peligro la sostenibilidad del acuífero (Rivera, 2018). 
Estas oposiciones en cuanto a leyes e instrumentos políticos causan conflictos entre las autoridades administrativas y la población. Con ello, aumenta la construcción de pozos informales que ponen en riesgo la sostenibilidad del acuífero.

\subsection{Prácticas sostenibles}

A partir de lo expuesto, al considerar la importancia de la producción de aceitunas en La Yarada Los Palos, es necesario implementar medidas que contribuyan con técnicas de cultivo más sostenibles. Entre ellas, se puede mencionar el riego por goteo deficitario, este consiste en regar con menor cantidad de la necesaria para una máxima producción, con el fin de optimizar el agua de irrigación (Cabeza y Jiménez, 2009). Este puede ser un riego deficitario sostenido o controlado. En el primero, las cantidades de riego se mantienen. Mientras que, en el controlado, la cantidad de agua varía respecto al estado fenológico. Es decir, varía en función a las características del cultivo en relación a los aspectos climáticos (Cabeza y Jiménez, 2009).

Otras medidas que pueden ser aplicadas incluyen la recarga artificial de los acuíferos; reducir las extracciones y mejorar las redes de distribución del agua que eviten las fugas y pérdidas; reutilizar aguas residuales; y modificar las técnicas de regadío a unas más eficientes (Pulido, 2001). La Autoridad Nacional del Agua, propone medidas de remediación como la recarga artificial del acuífero a través de trasvases, tratamiento de laderas, reutilización de aguas servidas y desalación (Pino, 2019). Asimismo, pueden establecerse áreas de protección especial de acuíferos o áreas de protección de captaciones, que permitan reparar y restaurar los acuíferos dañados y proteger los más vulnerables. Para ello es necesario tener el conocimiento correcto del acuífero, así como de su valor e importancia en el ecosistema (Custodio, 1996).

La agricultura familiar también se presenta como una alternativa para el desarrollo sostenible. Esto se debe a que es un sistema alimentario basado en la mano de obra familiar que busca la inclusión de las familias en el sector de los recursos productivos, asistencia técnica y servicios rurales financieros. Asimismo, incrementa el valor nutricional de la producción, el manejo de cosecha y post cosecha, la innovación tecnológica, la conservación de la biodiversidad y favorece la seguridad alimentaria (FAO, 2016).

En el caso del área de estudio, en noviembre de 2019 se iniciaron talleres de aprendizaje de agricultura familiar a cargo del MINAGRI. El proyecto también incluyó los distritos de Tacna y Ticaco, donde se planteó el desarrollo de escuelas de campo para la observación e intercambio de experiencias en buenas prácticas agrícolas. Entre los tres distritos involucrados, el área de acción del proyecto es de 145 hectáreas (SENASA, 2019). Por ello, considerando que solo en La Yarada Los Palos se ha registrado a 2020 cerca de 21000 hectáreas de cultivo, se deduce que este aún es un proyecto a pequeńa escala. 


\subsection{Limitaciones}

En el presente artículo, si bien los resultados se obtuvieron de forma remota, se reconoce la importancia del trabajo de campo. Ello, con el objetivo de hacer un contraste entre el área agrícola estimada a través de las imágenes Landsat 5 TM / Landsat 8 OLI y la extensión real en campo. De igual manera, permitiría corroborar las dinámicas entre el aumento de área agrícola y el crecimiento poblacional a través de métodos cualitativos como la aplicación de entrevistas y talleres. Asimismo, se recomienda para futuros estudios considerar otras variables como las oportunidades laborales sectoriales y los nuevos proyectos de agricultura familiar impulsados por el Estado que nos permitan comprender mejor las dinámicas del territorio y futuros cambios en la extensión agrícola.

\section{Conclusiones}

Este estudio contribuye con la generación de información respecto a la expansión de la superficie agrícola en el distrito de La Yarada Los Palos, por medio de fuentes secundarias, imágenes satelitales, información estadística y proyecciones. Asimismo, a través del mapa multitemporal, se identificó la expansión de la superficie agrícola para un periodo de veintiún años (2000-2020).

Respecto a esta expansión, se determinó que del año 2000 a 2020 hubo un incremento de 15 219,05 hectáreas, es decir aumentó en un 265,84\%, donde el periodo de mayor crecimiento en total fue el que transcurrió entre los años 2010 y 2015 con un 113\% de aumento. Además, se estimó que a 2030 habría un total de 42021 hectáreas cultivadas, lo que significa un aumento del $200,64 \%$ para los próximos diez años. Se estimó que esta expansión se daría en la zona central y sudeste del distrito, en el espacio clasificado como NU-PA, principalmente en las áreas cercanas a pozos, con bajas pendientes y pocas viviendas.

La Yarada Los Palos ha pasado de ser un territorio árido con un potencial agrícola limitado a ser una zona de cultivos. El aumento del espacio cultivado se relaciona con el crecimiento de la población a lo largo de los ańos y al aumento de disponibilidad de pozos para uso agrícola. Este hecho impulsó el desarrollo, mejora de la producción y exportación de cultivos, específicamente de las aceitunas.

La ampliación de la frontera agrícola ha conllevado un aumento de la explotación del acuífero costero que ha provocado un balance hídrico negativo, el cual perjudica la seguridad hídrica y la estabilidad del ecosistema. Pese a la existencia de mecanismos legales para su protección, los diferentes programas para el desarrollo y el modelo de agricultura actual han causado impactos en la sostenibilidad del acuífero. En este sentido, es importante considerar las prácticas sostenibles mencionadas, con el fin de mejorar el aprovechamiento del agua subterránea. 
Por último, a través de este estudio se observa cómo la teledetección constituye una herramienta relativamente nueva con la que es posible trabajar temas como la expansión agrícola. Por último, este estudio demuestra la importancia del desarrollo de investigaciones multidisciplinarias en la comprensión de la complejidad de temas como la expansión agrícola y su implicancia en temas sociales, económicos y ambientales.

\section{REFERENCIAS}

Ariza, A. (2013). Descripción y Corrección de Productos Landsat 8 LDCM. Instituto Geográfico Agustin Codazzi. Recuperado de: https://www.un-spider.org/sites/default/ files/LDCM-L8.R1.pdf

Autoridad Nacional del Agua (ANA). (2017). Observatorio de aguas subterráneas - SNIRH. Recuperado de http://snirh.ana.gob.pe/visorPozos/.

Banco Central de Reserva del Perú (BCRP). (2013). Informe económico y social - Región Tacna. Encuentro Económico. Recuperado de: https://www.bcrp.gob.pe/docs/Proyeccion-Institucional/Encuentros-Regionales/2013/tacna/ies-tacna-2013.pdf

Cabeza, C. \& Jiménez, M. (2009). Prácticas para una producción sostenible de olivar en Andalucía. Córdoba, Argentina. Recuperado de: https://www.academia.edu/32104121/ Olivar_sostenible_Pr\%C3\%A1cticas_para_una_producci\%C3\%B3n_sostenible_de_ olivar_en_Andaluc\%C3\%ADa

Custodio, E. (1996). Explotación racional de las aguas subterráneas. Acta Geológica Hispánica, 30 (1-3), 21-48.

Dirección Regional de Agricultura, Región Tacna. (2017). Producción y Exportación de aceitunas - 2017. [presentación de diapositivas]. Recuperado de: http://www.agritacna. gob.pe/gestores/estadistica/of_ol_estadidet_e/archivos/2778343429_4387653883.pdf

Foraquita, G. (2017). Infraestructura Administrativa de Gestión para Mejorar la Participación y Organización de los Pobladores del Distrito La Yarada-Los Palos-Tacna (Tesis de pregrado). Universidad Privada de Tacna, Tacna, Perú. Recuperado de: http://repositorio. upt.edu.pe/bitstream/UPT/231/1/Foraquita-Quiroz-Gustavo.pdf

Frías, M.; Fernández, J. \& Sordo, C. (2012). Estadística-Temas 2: Modelos de regresión. [presentación de diapositivas]. Universidad de Canbria. Recuperado de: https://ocw. unican.es/pluginfile.php/1156/course/section/1396/tema_02.pdf

Gobierno Regional de Coquimbo. (2000). Estimación de la demanda de agua en los cultivos. Recuperado de: http://bibliotecadigital.ciren.cl/bitstream/handle/123456789/9851/ CNR-0244.pdf?sequence $=1$ \&isAllowed $=y$

Instituto Nacional de Estadística e Informática (INEI). (2014a). Inequidades de Género en la Actividad Agropecuaria. IV Censo Nacional Agropecuario 2012 [Libro electrónico]. Lima, Perú. Recuperado de: https://www.inei.gob.pe/media/MenuRecursivo/publicaciones_digitales/Est/Lib1185/cap03.pdf 
Instituto Nacional de Estadística e Informática (INEI). (2014b). Capitulo 12: Agrario. En INEI, Compendio estadístico Perú 2014 (pp. 939 - 1021). Lima, Perú. Recuperado de: https://www.inei.gob.pe/media/MenuRecursivo/publicaciones_digitales/Est/ Lib1173/cap12/cap12.pdf

Instituto Nacional de Estadística e Informática (INEI). (2017). Censos Nacionales 2017: XII de población, VIII de vivienda y III de comunidades indígenas. Lima, Perú. Instituto Nacional de Estadística e Informática. Recuperado de: https://censos2017.inei.gob. pe/redatam/

Instituto Nacional de Estadística e Informática (INEI), Ministerio Nacional de Agricultura y Riego (MINAGRI). (2012). IV Censo Nacional Agropecuario 2012. Recuperado de http://proyectos.inei.gob.pe/web/DocumentosPublicos/ResultadosFinalesIVCENAGRO.pdf

Klitgaard, F. (2011). Line or scatter chart? Microsoft 365. Recuperado de: https://www. microsoft.com/en-us/microsoft-365/blog/2011/08/30/line-or-scatter-chart/

Ley $N^{\circ}$ 30358. Diario oficial del Bicentenario El Peruano, Lima, Perú, 8 de noviembre de 2015

Marini, M. (2008). El avance de la Frontera Agrícola en el área adyacente al Sistema Sierras de la Ventana (Buenos Aires, Argentina). Investigaciones Geográficas, (47), 111-121. https://doi.org/10.14198/INGEO2008.47.06

Ministerio de Agricultura y Riego (MINAGRI). (2019). Plan Nacional de Cultivos. Campańa Agrícola 2019-2020. Ministerio de Agricultura y Riego. Recuperado de: https://cdn.www.gob.pe/uploads/document/file/471867/Plan_Nacional_de_ Cultivos_2019_2020b.pdf

Ministerio de Agricultura y Riego (MINAGRI). (s.f). Perfil Productivo Regional. Recuperado de: https://app.powerbi.com/view?r=eyJrIjoiMDNmYzU1Y2ItM2I1Ny00Y2E5LWEzOGMtM2Y4Y2VmNmZiNWQzIiwidCI6IjNmMmVjNzcwLWMxYjEtND EzYy05ZmY5LTRjOWY3MDA1OWYxOCJ9

Ministerio de Energía y Minas (MINEM). (2020). Estudio Evaluaciones Ambientales Complementarias del Proyecto Agroenergético Central Hidroeléctrica Pucará. Recuperado de: http://www.minem.gob.pe/minem/archivos/file/DGGAE/ARCHIVOS/estudios/ EIAS\%20-\%20electricidad/EIA/EIA\%20C.H.\%20PUCARA\%20ACTUALIZADO/ CAPITULO\%20V.pdf

Municipalidad Distrital de La Yarada los Palos. (2018). Plan de desarrollo local concertado 2017-2021. Recuperado de: http://www.munilayaradalospalos.gob.pe/Inicio/ detalle/m49

Municipalidad Distrital de La Yarada Los Palos. (2020). Portal de transparencia: Proyectos de inversión. Recuperado de: https://www.transparencia.gob.pe/reportes_directos/pte_ transparencia_pro_inv.aspx?id_entidad=18783\&id_tema $=26 \& v e r=1 \# . Y B c a 7-h K g 2 x$ 
Oficina Nacional de Evaluación de Recursos Naturales (ONERN). (1976). Mapa Ecológico del Perú. Guía explicativa. Recuperado de: http://www.keneamazon.net/Documents/ Publications/Virtual-Library/Maps/Mapa-Ecologico-Del-Peru-1976.pdf

Organización de las Naciones Unidas de la Alimentación y la Agricultura (FAO). (2016) Agricultura sostenible. Una herramienta para fortalecer la seguridad alimentaria y nutricional en América Latina y el Caribe. Recuperado de: http://www.fao.org/3/a-i5754s.pdf

Paruelo, J.M.; Guerschman, J. \& Verón, S. (2005). Expansión agrícola y cambios en el uso del suelo. Ciencia Hoy, 15 (87), 14-23.

Peña, F.; Cotrina, G. \& Acosta, H. (2009). Hidrogeología de la Cuenca del Río CaplinaRegión Tacna (Boletín $\mathrm{N}^{\circ} 1$, Serie H). Lima, Perú: INGEMMET. Recuperado de: https://repositorio.ingemmet.gob.pe/handle/20.500.12544/368

Presidencia del Consejo de Ministros (PCM). (2015). Gobierno envía al Congreso proyecto de ley que crea distrito de La Yarada Los Palos, en Tacna. Recuperado de: http://www. pcm.gob.pe/2015/08/gobierno-envia-al-congreso-proyecto-de-ley-que-crea-distritode-la-yarada-los-palos-en-tacna/

Pineda, O. (2011). Análisis de Cambio de Uso de Suelo Mediante Percepción Remota en el Municipio de Valle de Santiago (Tesis de maestría). Centro Público de Investigación CONACYT, México D.F., México.

Pino, E. (2019). El acuífero costero La Yarada, después de 100 años de explotación como sustento de una agricultura en zonas áridas: una revisión histórica. IDESIA (Chile), 37(3), 39-45. https://doi.org/10.4067/S0718-34292019000300039

Pino, E. \& Coarita, F. (2018). Caracterización hidrogeológica para determinar el deterioro de la calidad del agua en el acuífero La Yarada Media. Journal of High Andean Research, 20(4), 477-490. https://doi.org/10.18271/ria.2018.424

Programa de las Naciones Unidas para el Desarrollo (PNUD). (2018). Índice de Desarrollo Humano, Perú 2018. [Excel]. Recuperado de: https://www.pe.undp.org/content/dam/ peru/docs/Publicaciones\%20pobreza/idh2019/IDH\%202018.xlsx

Pulido, A. (2001). Sobreexplotación de acuiferos y desarrollo sostenible. Departamento de Hidrogeología, Universidad de Almería, España, 115-132.

Ramos, D. (2019) Combinación de bandas en imágenes de satélite Landsat y Sentinel. MappingGis. Recuperado de: https://mappinggis.com/2019/05/combinaciones-debandas-en-imagenes-de-satelite-landsat-y-sentinel/\#Usos_agricolas

Rivera, L. (2018). La Agencia de los Pozos Subterráneos y la Geografia Histórica del Distrito La Yarada-Los Palos, Tacna (Tesis de pregrado). Pontificia Universidad Católica del Perú, Lima, Perú.

Ruiz, V., Savé, R. \& Herrera, A. (2013). Análisis Multitemporal del Cambio de Uso del Suelo en el Paisaje Terrestre Protegido Miraflor Moropotente Nicaragua, 1993-2011. Ecosistemas: revista cientifica de Ecología y Medio Ambiente, 22 (3), 117-123. https:// doi.org/10.7818/ECOS.2013.22-3.16 
Servicio Geológico de los Estados Unidos (USGS). (s.f.) Landsat Satellite Missions. Recuperado de: https://www.usgs.gov/land-resources/nli/landsat/landsat-satellite-missions?qtscience_support_page_related_con=2\#qt-science_support_page_related_con

Servicio Nacional de Sanidad Agraria (SENASA). (2019). MINAGRI fortalece agricultura familiar a través de escuelas de campo. SENASA contigo. Recuperado de: https://www. senasa.gob.pe/senasacontigo/tacna-minagri-fortalece-agricultura-familiar-a-traves-deescuelas-de-campo/

Tarrillo, L. (2019). Análisis de los Cambios de Cobertura y Uso de Suelo con Imágenes Satelitales del Distrito de Tacabamba Años 2003 y 2018 (Tesis de pregrado). Universidad Nacional de Cajamarca, Cajamarca, Perú.

Zarta, P. (2018). La sustentabilidad o sostenibilidad: un concepto poderoso para la humanidad. Tabula Rasa, (28), 409-423. https://doi.org/10.25058/20112742.n28.18

Zorogastúa, P., Quiroz, R. \& Garatuza, J. (2011). Evaluación de Cambios en la Cobertura y Uso de la Tierra con Imágenes de Satélite en Piura - Perú. Ecología Aplicada, 10(1), 11-22. https://doi.org/10.21704/rea.v10i1-2.409 


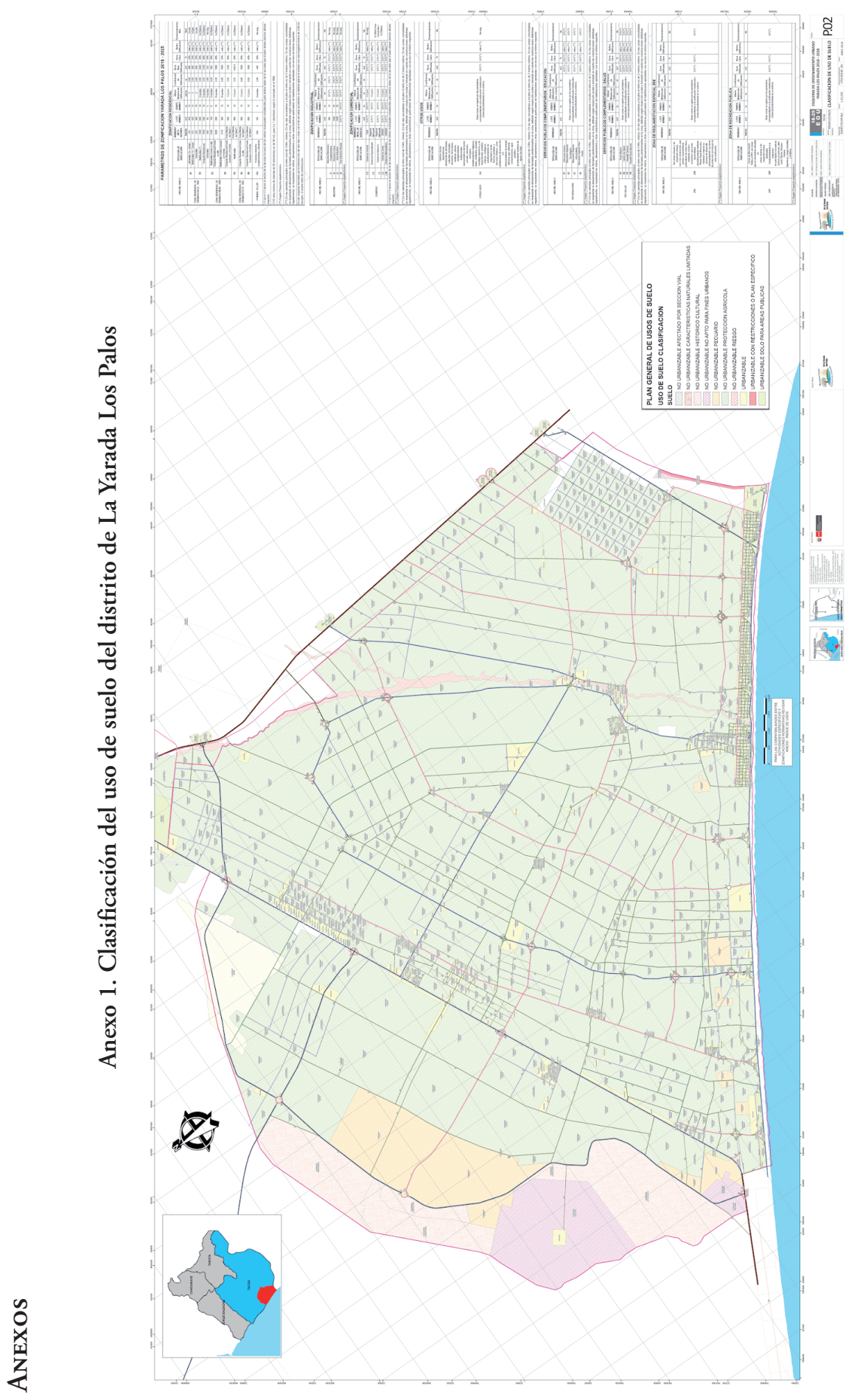

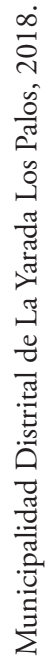

